Anim. Reprod., Belo Horizonte, v.13, n.2, p.81-92, Apr./Jun. 2016

\title{
Relationships between follicle and corpus luteum diameter, blood flow, and progesterone production in beef cows and heifers: preliminary results
}

\author{
S.G.S. de Tarso, G.A. Apgar, M.O. Gastal, E.L. Gastal ${ }^{1}$ \\ Department of Animal Science, Food and Nutrition, Southern Illinois University, Carbondale, IL, USA.
}

\begin{abstract}
The aim of the present study in beef cattle was to investigate potential differences in follicle size and follicle wall-blood flow between cows and heifers and to compare follicle wall-blood flow between smaller and larger follicles. Cows and heifers were treated with a synchronization protocol and follicles and CLs were measured and evaluated for blood flow. Pregnancy diagnosis was performed on day 50 of the protocol. Cows had larger $(P<0.008)$ follicles than heifers. Cows, heifers, and pregnant and non-pregnant cows did not differ $(\mathrm{P}>0.05)$ in $\mathrm{CL}$ diameter, CL blood flow, and plasma progesterone concentrations. Moderate correlations between follicle diameter and follicle blood flow were observed for cows $(\mathrm{r}=0.51 ; \mathrm{P}<0.002)$ and heifers $(\mathrm{r}=0.61 ; \mathrm{P}<0.0001)$. Pregnant cows tended $(\mathrm{P}<0.1)$ to have larger follicles between 12 to $60 \mathrm{~h}$ before ovulation, and had larger $(\mathrm{P}<0.05)$ follicles than non-pregnant cows at hour 24 before ovulation and at hour 12 before maximum values. Pregnant cows had greater $(\mathrm{P}<0.05)$ follicle blood flow than non-pregnant cows at hours -36 and -24 before maximum values. Follicle blood flow was greater $(\mathrm{P}<0.002)$ in the large follicles compared with the small follicles, and tended $(\mathrm{P}<0.06)$ to be greater than in medium follicles. Moderate to strong correlations were found between follicle blood flow and diameter of small $(\mathrm{r}=0.59 ; \mathrm{P}<0.002)$, medium $(\mathrm{r}=0.50 ; \mathrm{P}<0.02)$, and large $(\mathrm{r}=0.71 ; \mathrm{P}<0.0001)$ follicles. Pregnancy rates were similar $(\mathrm{P}>0.05)$ among all follicle diameter categories. In conclusion, synchronized beef cows and pregnant cows had larger follicles and greater blood flow than heifers and non-pregnant cows, and follicle wall blood flow was closely associated with increasing follicle diameter.
\end{abstract}

Keywords: blood flow, color-Doppler, cow, follicle, ultrasonography.

\section{Introduction}

Vascular perfusion in ovarian structures, using color-Doppler ultrasonography, has been the focus of numerous studies in different species for more than 20 years (Janson et al., 1981; Bourne et al., 1991; Acosta and Miyamoto, 2004; Gastal et al., 2006; Oliveira et al., 2014; Miró et al., 2015). Currently, a greater vascular support to organs and tissues is synonymous with function and hormonal production by the ovaries (Acosta et al., 2002, 2003). In the ovaries, preovulatory follicle (POF) wall blood flow has been used to study reproductive success in farm animals (Ginther and Utt, 2004; Herzog and Bollwein, 2007; Viana et al., 2013).
In cattle, reproductive performance is of great importance for the success of modern production systems and is broadly studied in both the beef and dairy industries (Macmillan et al., 2003; Wiltbank et al., 2011). Additionally, modern cattle systems try to overcome the low fertility rates that are commonly associated with high production levels (Lopez et al., 2004, 2005) by increasing herd size. Therefore, the use of hormonal estrous synchronization is a crucial tool for the reproductive management of the beef and dairy cattle industries (Baruselli et al., 2004; Lauderdale, 2008; Bisinotto et al., 2014). Concerns with how the synchronization protocols in cattle can interfere with follicle growth (Adams et al., 2008; Atkins et al., 2010a), ovulatory capacity (Sartori et al., 2001; Gimenes et al., 2008), and oocyte maturity (Pohler et al., 2012; Geary et al., 2013) during artificial insemination (AI) programs have produced a wide range of research data designed to study the fertility rates under controlled hormonal conditions (Wiltbank et al., 2011; Bó et al., 2012; Wiltbank and Pursley, 2014).

The optimal size of the ovulatory follicle under hormonal protocols is still a major area of interest, since well-balanced follicular growth is dependent upon multiple hormonal interactions (Sartori et al., 2001; Colazo et al., 2008; Pfeifer et al., 2009; Sá Filho et al., 2010; Dadarwal et al., 2013; Wiltbank et al., 2014), breed characteristics and environmental adaptation (Bó et al., 2003; Baruselli et al., 2004; Sartori and Barros, 2011), and reproductive cyclicity status (Atkins et al., 2010a, b). The ovulatory follicle size in cows and heifers can be assessed from distinct studies; however, no experimental design with animals under the same conditions and without the interference of suckling calves has been conducted in beef cattle. A large range of ovulatory follicle sizes has been reported for Bos taurus ( $<10$ to $18 \mathrm{~mm}$; Lamb et al., 2001; Perry et al., 2005) and Bos indicus ( $<9$ to $17 \mathrm{~mm}$; Meneghetti et al., 2009; Sá Filho et al., 2009) beef cows, and Bos taurus $(<10$ to $16 \mathrm{~mm}$; Perry et al., 2007) and Bos indicus $(<6$ to $16 \mathrm{~mm}$; Dias et al., 2009) beef heifers. The relationship between ovulatory follicle size and reproductive success has been shown in beef heifers (Perry et al., 2007) and postpartum cows with suckling calves (Perry et al., 2005), where ovulating follicles $<11$ $\mathrm{mm}$ in diameter were more likely to decrease pregnancy rates and increase late embryonic/fetal mortality. In contrast, dairy cows that ovulate large follicles (e.g., $>17 \mathrm{~mm}$ ) have been associated with greater progesterone (P4) concentration but reduced fertility when compared to those that ovulated follicles between 11 to $17 \mathrm{~mm}$ (Vasconcelos et al., 2013). 
On the other hand, follicle size is not the only parameter that predicts success at the end of the synchronization protocol. Other factors such as the association between larger follicle sizes and greater follicle wall blood flow has confirmed higher rates of establishment of pregnancy (Siddiqui et al., 2009a), greater rates of oocyte recovery, and higher incidence of in vitro oocyte cleavage and embryo development in dairy heifers (Siddiqui et al., 2009b). Associations between other aspects of intrafollicular hormonal environment such as the estradiol concentration on the day of AI in lactating Holstein cows (Lopes et al., 2007) and follicle blood flow with IGF-1 levels in Murrah buffaloes (Pandey et al., 2011; Varughese et al., 2014) have been reported. Therefore, despite the existence of studies correlating ovulatory follicle size and reproductive success, no associations of a greater POF wall blood flow with the increase in follicle diameter have been done comparing cows and heifers. Additionally, no previous information about the relationship between follicle wall blood flow and follicle size and its influence on pregnancy rates is available in beef cattle.

Therefore, the aim of the present study in beef cattle was to investigate potential differences in follicle size and wall blood flow between cows and heifers and to study the relationship of follicle blood flow between smaller and larger follicles. Additionally, this study aimed to investigate the relationship between the increase in follicle size and an increase in follicle blood flow, and pregnancy rates. The hypotheses tested in the present study were as follows: (1) cows have larger ovulatory follicle sizes and a more vascularized follicle wall than heifers; (2) follicle blood flow increases linearly, following an increment according to follicle size; and (3) synchronized beef cattle with larger follicles and greater follicle wall blood flow produce greater pregnancy rates than animals with smaller and less vascularized follicles.

\section{Materials and Methods}

Animals

Animal procedures were performed and approved according to the Institutional Animal Care and Use Committee of Southern Illinois University (Protocol \#12-045) and conducted in accordance with the US Government Principles for the Utilization and Care of Vertebrate Animals Used in Testing, Research and Training (http:/grants.nih.gov/grants/olaw/references/ phspol.htm\#USGovPrinciples, accessed on 8 January 2013). Aberdeen Angus beef cattle (Bos taurus; cows, $n$ $=21$; heifers, $\mathrm{n}=6$ ) from the Beef Center of the College of Agricultural Sciences, Southern Illinois University, were used in this study. Cows were non-lactating and 2.8 years old, and heifers were 1.2 years old. The body condition score was 5.0 (on a scale of $1-9$, where $1=$ thin and $9=$ obese; Eversole et al., 2009). Animals were housed in free stalls, had unrestricted access to water and mineral salt, and were fed hay and rations twice daily.

\section{Study design}

Animals were treated with a 7-day Co-Synch + CIDR protocol (Fig. 1). Heifers and cows were treated on the day of AI with a second dose of GnRH $(86 \mathrm{mg}$ per animal) at 54-56 $\mathrm{h}$ and 60-66 h after CIDR removal, respectively. The same technician performed the AIs using semen from the same bull and batch. Beginning on day 7 of the protocol, all follicles $\geq 7 \mathrm{~mm}$ in diameter were measured and the percentage of the follicular wall with blood flow signals was evaluated using B-mode and color-Doppler ultrasonography, respectively. Ultrasound examinations were performed every $12 \mathrm{~h}$ for approximately 3.5 days until ovulation. After ovulation, cows and heifers were scanned daily for 6 days and the same parameters were evaluated for the corpus luteum (CL). Pregnancy was confirmed via ultrasonography on day 50 of the protocol (30-40 days after ovulation).

\section{Ultrasonography and blood flow evaluation}

A portable duplex color-Doppler ultrasound machine (Sonoscape S8; Universal Medical Systems, Inc., Bedford Hill, NY, USA) connected to a linear probe (5.0-10.0 MHz, $46 \mathrm{~mm}$ ) was used and all ultrasound scans were carried out by a single operator (S.G.S. de Tarso). The same settings of frequency and patterns of gain and color were chosen and kept constant throughout the study for all ultrasound examinations (Ginther, 1995). Three still images at the maximum dimension of each structure (follicle and CL) within each time point were taken and recorded and the diameter (average of height and width) was obtained. The assessment of blood flow was made subjectively by visual evaluation of the vascular percentage $(0-100 \%)$ of the follicle wall and CL area filled with color signals of blood flow (Ginther, 2007). Blood flow was evaluated after a slow continuous motion of the probe on the surface of the follicle or CL until the entire circumference of the structure was displayed at least three times (Ginther, 2007; Siddiqui et al., 2009b).

\section{Follicle blood flow using colored pixel area}

Pixel area of the follicle blood flow was used to test possible differences between the results of subject and object techniques among follicle size categories. Digital images were exported in DICOM and JPG format from the hard drive of the ultrasound machine to a computer. Three different images with maximum Doppler signals of blood flow from the same follicle and the same time points were processed for the quantification of the area with colored pixels. Colored areas or pixel aggregates were manually selected, extracted, and saved using Adobe Photoshop software (Ginther and Utt, 2004; Ginther, 2007). Colored pixels were considered to be part of the follicle wall and CL when found within $3 \mathrm{~mm}$ from the edge of the structure (Fig. 2). Image $J^{\circledR}$ software was used to measure the area of colored Doppler signals (Ginther and Utt, 2004; Ginther, 2007). The mean area $\left(\mathrm{mm}^{2}\right)$ of colored pixels in the follicle wall from three images in each time point was used for each animal.

\section{Blood collection and hormone assays}

Before each ultrasound examination, blood samples were collected from the coccygeal vein every $12 \mathrm{~h}$ until ovulation and daily until day 20 . Blood samples 
were immediately placed on ice and centrifuged within $1 \mathrm{~h}$ at $1500 \mathrm{~g}$ for $20 \mathrm{~min}$ at $4^{\circ} \mathrm{C}$. Plasma samples were separated and stored at $-20^{\circ} \mathrm{C}$ until $\mathrm{P} 4$ concentrations were determined. Plasma P4 concentrations were assessed by solid-phase radioimmunoassay kits containing antibody-coated tubes and ${ }^{125}$ I-labelled P4 (Coat-a-Count; Diagnostic Products, Los Angeles, CA, USA), as described previously (Ginther et al., 2007). The intra- and interassay $\mathrm{CVs}$ and sensitivity were $6.2 \%$, $8.4 \%$, and $0.02 \mathrm{ng} / \mathrm{ml}$, respectively.

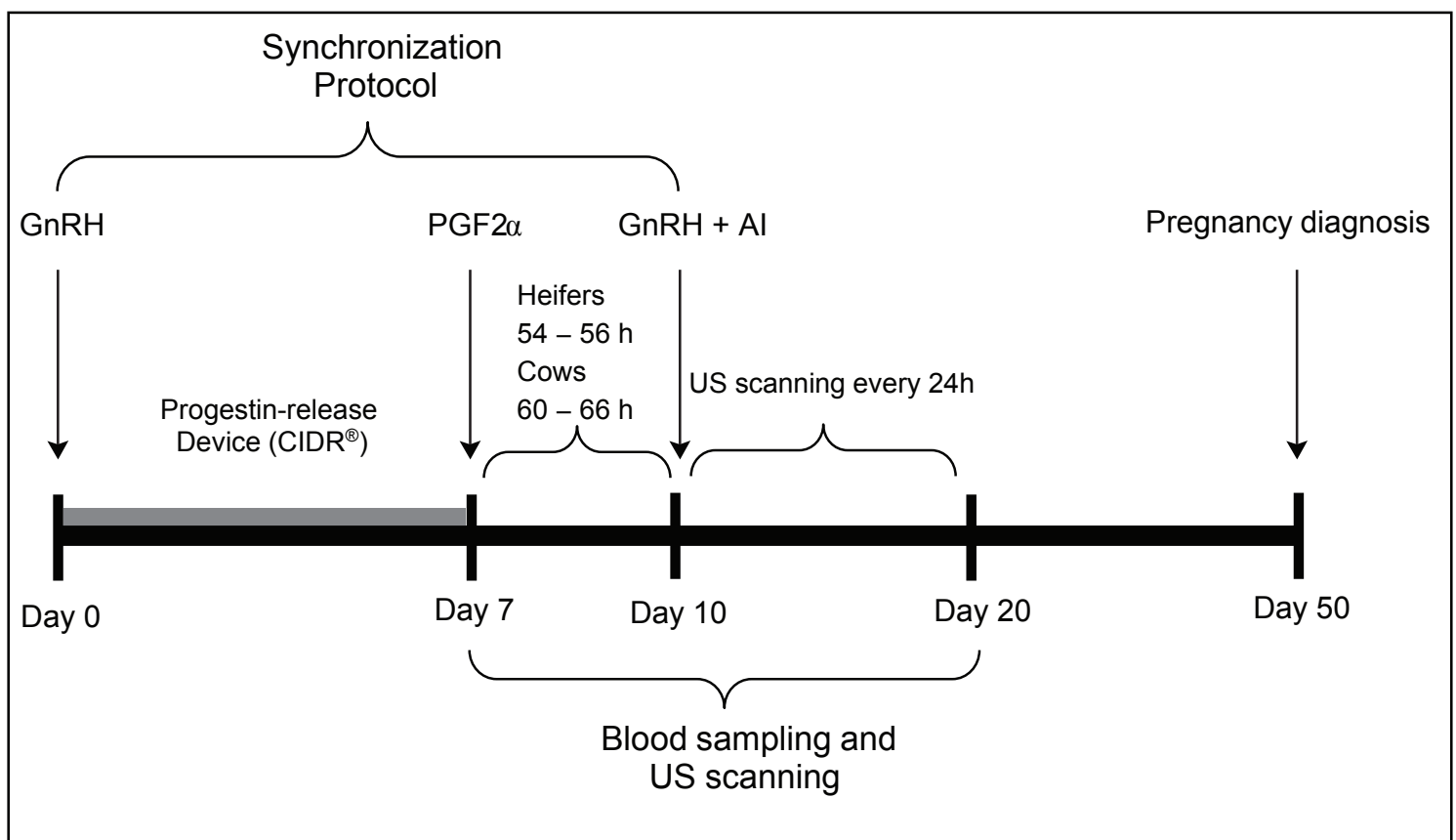

Figure 1. Synchronization protocol and experimental design. On day 0 of the protocol, cows and heifers were injected with a gonadotrophin releasing hormone analog ( $\mathrm{GnRH}$ analog) (86 mg per animal, i.m.; gonadorelin diacetate tetrahydrate; Fertagyl; Intervet, Unterschleissheim, Germany). On the same day, an intravaginal P4releasing device (Eazi-Breed CIDR; Pfizer Animal Health, New York, NY, USA) was inserted in all animals. A prostaglandin (PG) F2a analog (dinoprost tromethamine; Lutalyse; Pfizer Animal Health; 25 mg per cow, i.m.) was administered 7 days later, at which time the CIDR was removed. On day 10, a second injection of GnRH and AI was performed at 54-56 $\mathrm{h}$ and 60-66 $\mathrm{h}$ after CIDR removal in heifers $(\mathrm{n}=6)$ and cows $(\mathrm{n}=21)$, respectively. Ultrasound pregnancy diagnosis was performed on day 50 of the protocol (30-40 days after ovulation).
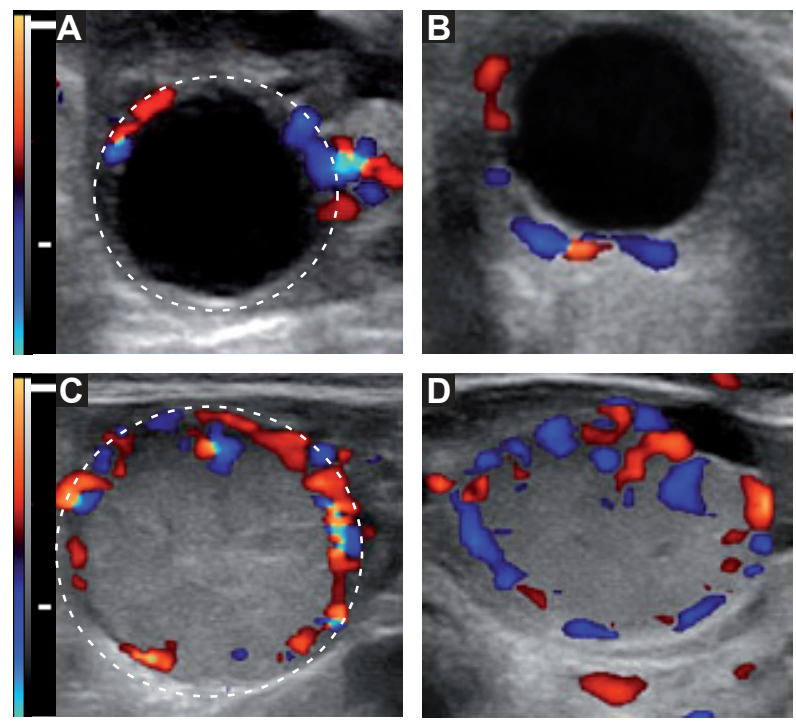

Statistical analyses

Statistical analyses were performed using a MIXED procedure in SAS version 9.2 (SAS Institute, Cary, NC, USA) with a repeated statement to account for autocorrelation between sequential measurements. Datasets that were not normally distributed were
Figure 2. Color-Doppler ultrasonograms of two preovulatory follicles (POFs) and corpora lutea (CLs) from two cows [Cow 1 (A, C); Cow $2(\mathrm{~B}, \mathrm{D})]$. POFs (A) $72 \mathrm{~h}$ and (B) $36 \mathrm{~h}$ before ovulation. CLs (C) $114 \mathrm{~h}$ and (D) $144 \mathrm{~h}$ post-ovulation. Note the white dashed line surrounding the colored pixel area $(\mathrm{A}, \mathrm{C})$ to be considered for the objective evaluation.

transformed by the natural logarithm or ranks before analysis. Data were normalized to either time of ovulation or maximum values obtained for the POF, CL, and $\mathrm{P} 4$ concentrations. Student unpaired t-test was used to locate differences between two means at maximum blood flow among distinct follicle size categories. The pregnancy rate among follicle size categories was 
analyzed by Fisher's exact test. Pearson's correlation analysis was used to compare POF diameter and blood flow and CL diameter and blood flow. The correlations between parameters were classified as weak $(\mathrm{r} \leq 0.35)$, moderate $(\mathrm{r}=0.36-0.67)$, or strong $(\mathrm{r}=0.68-1.00$; Taylor, 1990). Data were expressed as mean \pm SEM, unless otherwise indicated. A probability of $\mathrm{P}<0.05$ indicated that a difference was significant, and $\mathrm{P}>0.05$ and $<0.10$ indicated that a difference approached significance.

\section{Results}

All animals had single ovulations. Using data normalized to ovulation (hours -60 to -12 ) or normalized to maximum values (hours -48 to 0 ), cows had larger $(\mathrm{P}<0.008)$ follicles (Fig. $3 \mathrm{~A}$ and $\mathrm{B})$ and greater $(\mathrm{P}<0.01)$ follicle blood flow (Fig. $3 \mathrm{C}$ and $\mathrm{D})$ than heifers. Corpus luteum diameter and blood flow, and plasma $\mathrm{P} 4$ concentrations were not different $(\mathrm{P}>0.05)$ between cows and heifers. However, there was an overall increase $(\mathrm{P}<0.0001)$ in follicle and $\mathrm{CL}$ diameter, follicle and CL blood flow, and plasma P4 concentrations, which occurred along the time points before and after ovulation. Moderate correlations between follicle diameter and follicle blood flow were observed for cows $(\mathrm{r}=0.51$; $\mathrm{P}<0.002)$ and heifers $(\mathrm{r}=0.61 ; \mathrm{P}<0.0001)$. Additionally, CL diameter and blood flow were moderately correlated $(\mathrm{r}=0.60 ; \mathrm{P}<0.0001)$.

\section{Follicle diameter}
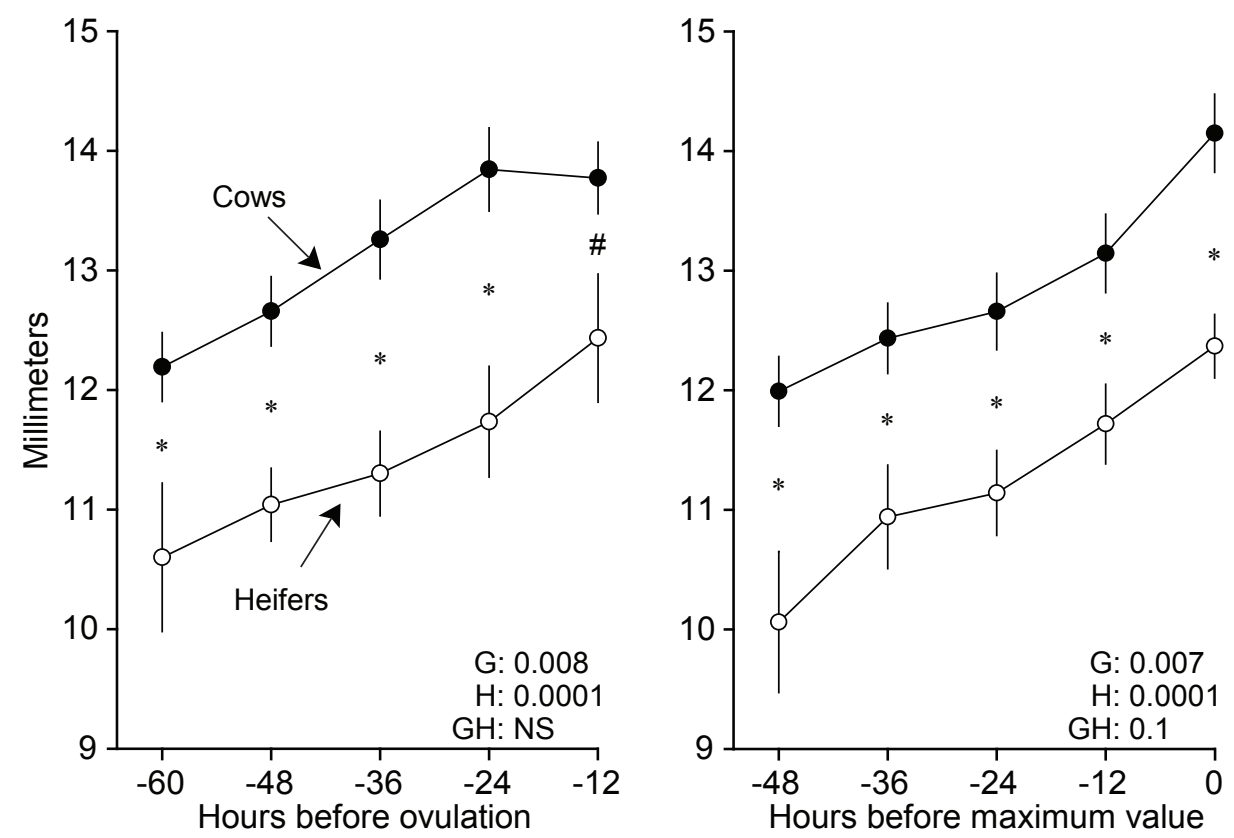

\section{Follicle blood flow}
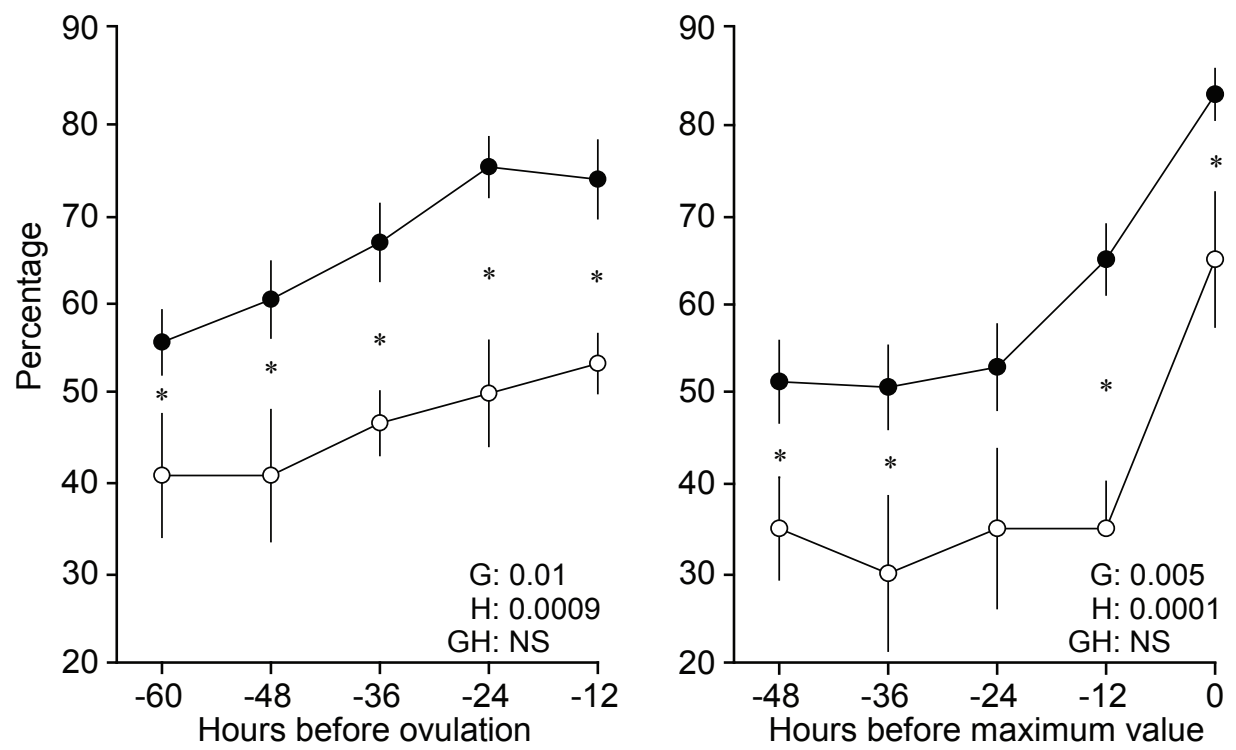

Figure 3. Comparisons of preovulatory follicle diameter (A - B) and blood flow (C - D) between beef cows $(n=21)$ and heifers $(n=6)$. Data were normalized to ovulation (left side) and to maximum values (right side). 
For comparisons between pregnant and nonpregnant animals, heifers were excluded from the analysis due to the reduced number of animals and to avoid confounding effects between different animal categories. Cows that became pregnant tended $(\mathrm{P}<0.1)$ to have larger follicles than cows that did not become pregnant between hours 60 to 12 before ovulation. However, cows that became pregnant had greater $(\mathrm{P}<0.05$; Fig. $4 \mathrm{~A}$ and $\mathrm{B}$ ) follicle diameter than cows that did not become pregnant at hour 24 before ovulation and hour 12 before maximum follicle diameter. Follicle blood flow did not differ $(\mathrm{P}>0.05)$ between pregnant and non- pregnant cows with data normalized to ovulation (Fig. 4C). Nevertheless, follicle blood flow in pregnant cows tended $(\mathrm{P}<0.1)$ to be greater when data were normalized to maximum values. A group by hour interaction revealed that pregnant cows had greater $(\mathrm{P}<0.05)$ follicle blood flow than non-pregnant cows at hours -36 and -24 (Fig. 4D). However, there were no significant differences observed between pregnant and non-pregnant cows for CL diameter and blood flow, or for plasma P4 concentrations until 6 days after ovulation in both normalized dataset (data not shown).

\section{Follicle diameter}
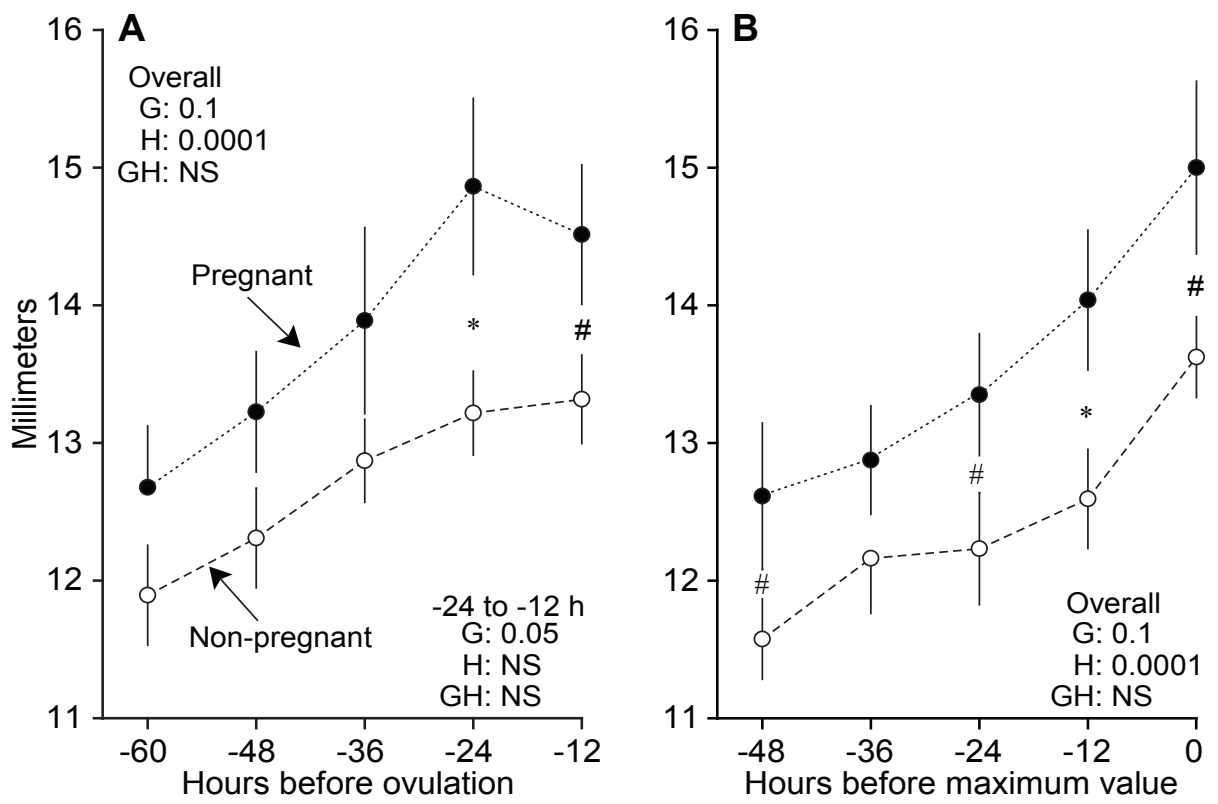

Follicle blood flow
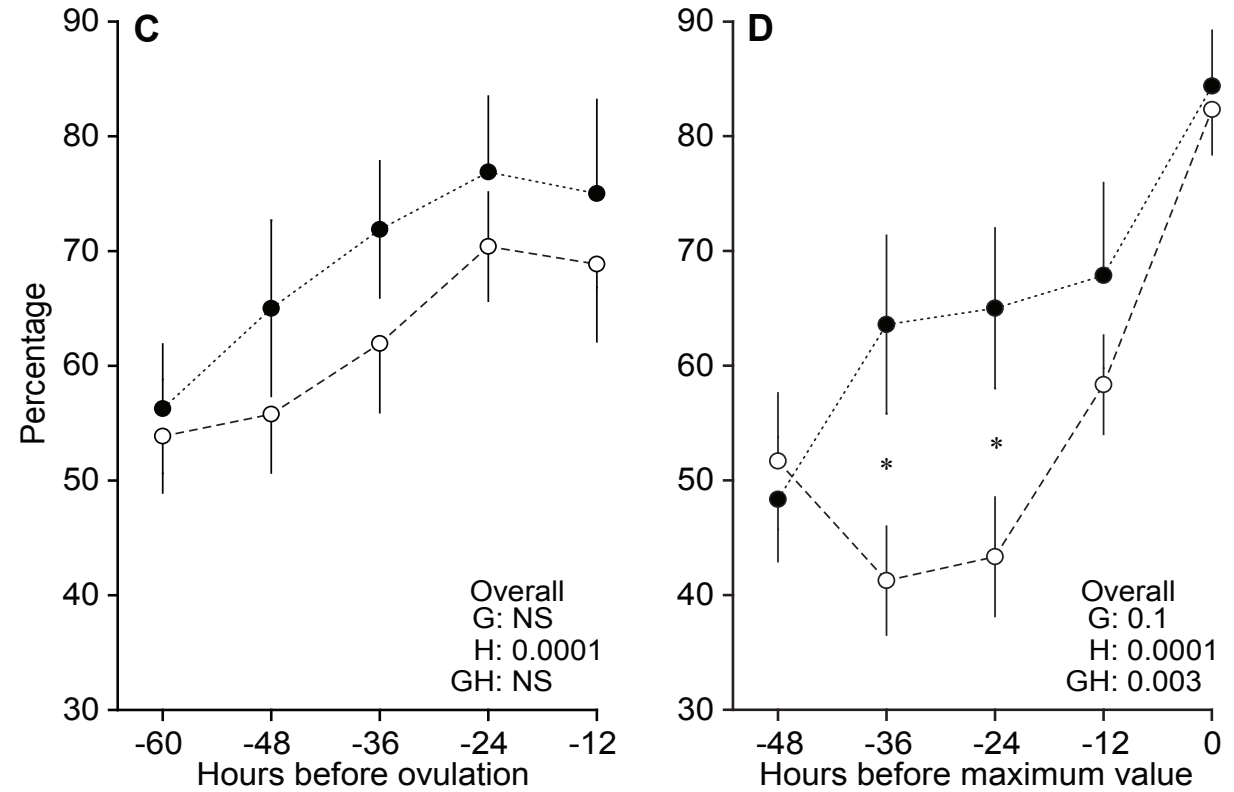

Figure 4. Comparisons of preovulatory follicle diameter (A - B) and blood flow $(C-D)$ between pregnant $(n=9)$ and non-pregnant $(\mathrm{n}=12)$ beef cows. Data were normalized to ovulation (left side) and to maximum values (right side). 
To allow further analyses, the preovulatory follicles were classified according to size (diameter) categories as: small $(10.8-12.8 \mathrm{~mm})$, medium (13.2 $13.9 \mathrm{~mm})$, and large $(14.1-17.5 \mathrm{~mm})$, and normalized to maximum values (Fig. 5A). For these analyses, all individuals (cows and heifers) were grouped regardless of animal category. Sequential comparison of follicle blood flow (\%) among follicle categories showed the large follicle categories having greater $(\mathrm{P}<0.04)$ blood flow than small follicles between hours -48 to 0 (Fig. 5B). However, pixel evaluation of follicle blood flow showed that blood flow of the larger follicle category only tended $(\mathrm{P}<0.07)$ to be greater than the small follicle category, although differences between the two categories were observed at hours $-48,-12$, and 0 (Fig. 5C).
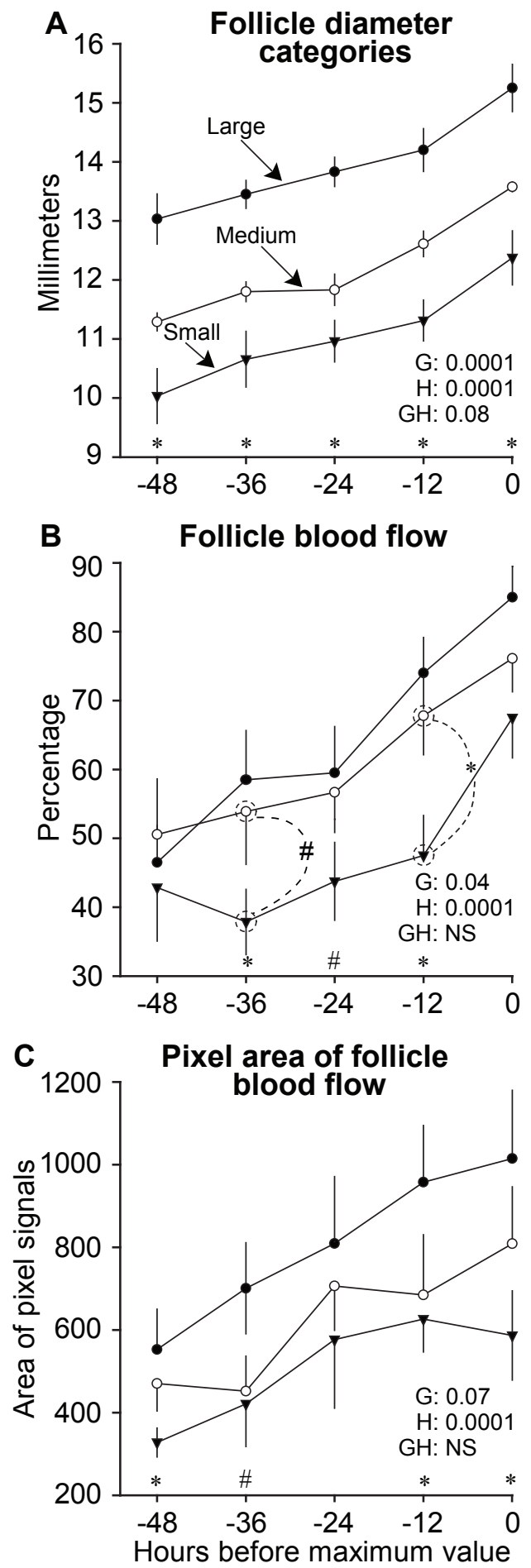

Figure 5. Comparisons of follicle diameter (A), percentage of blood flow (B), and pixel area of blood flow (C) according to the follicle diameter categories in cows and heifers $(n=27)$. Follicles were divided according to follicle size into three groups: small (10.8 - $12.8 \mathrm{~mm})$, medium (13.2 - 13.9), and large (14.1 - 17.5). 
Pearson correlation coefficient of sequential data of follicle blood flow, evaluated subjectively versus each follicle size category, showed moderate to strong correlations in small $(\mathrm{r}=0.59 ; \mathrm{P}<0.002)$, medium $(\mathrm{r}=$ $0.50 ; \mathrm{P}<0.02)$, and large follicles $(\mathrm{r}=0.71 ; \mathrm{P}<0.0001)$, respectively. Weaker correlations were detected between the objective pixel evaluation of follicle blood flow versus follicle size categories (small: $\mathrm{r}=0.30, \mathrm{P}<0.02$; medium: $\mathrm{r}=0.32, \mathrm{P}<0.004$; large: $\mathrm{r}=0.43, \mathrm{P}<0.0001$ ).

When the mean follicle blood flow subjective evaluation at the maximum value was obtained from each follicle category and analyzed with the respective pregnancy rates, follicle blood flow was greatest $(\mathrm{P}<0.002)$ for the large follicle category when compared with the small follicle category, and tended $(\mathrm{P}<0.06)$ to be greater than medium-size follicles. Although pregnancy rates were numerically greater $(50 \%)$ for the larger follicle category than the small $(25 \%)$ and medium $(22.2 \%)$ follicle categories, potentially because of the limited number of pregnant animals, no difference $(\mathrm{P}>0.05)$ was obtained among follicle categories for this end point (Fig. 6).

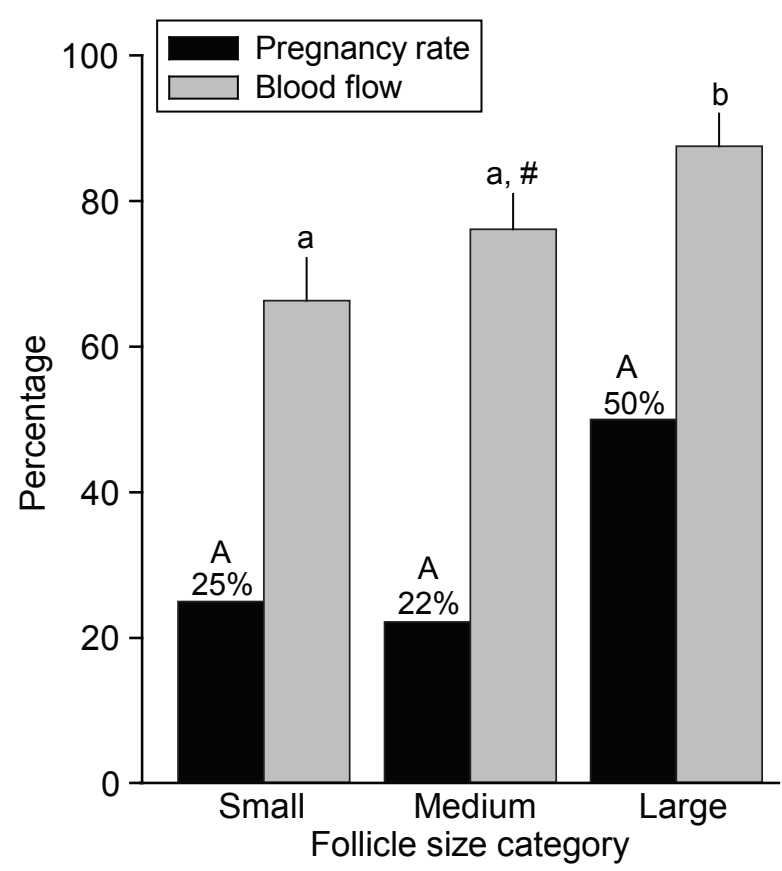

Figure 6. Comparisons of follicle blood flow between the follicle size categories (small, medium, and large) and its association with the pregnancy rates in beef cows $(n=21)$. Follicles were divided according to follicle size into three groups: small (10.8 - $12.8 \mathrm{~mm})$, medium (13.2 - 13.9), and large (14.1 - 17.5). ${ }^{\mathrm{a}, \mathrm{b}}$ Different superscripts indicate follicle blood flow difference among follicle categories. Follicle blood flow: small vs. large follicle category $(\mathrm{P}<0.002)$; small vs. medium $(\mathrm{P}=0.2)$; medium vs. large $(\mathrm{P}<0.06)$. ${ }^{\text {\# }}$ Represents that a tendency for a difference was approached when comparing medium vs. large follicle categories. ${ }^{A}$ Pregnancy rates did not differ $(\mathrm{P}>0.05)$.

\section{Discussion}

In this study we have demonstrated for the first time in beef cattle under hormonal treatment that cows had a greater follicle wall blood flow within $60 \mathrm{~h}$ before ovulation than heifers. In addition, the positive correlations obtained between follicular blood flow and diameter, and CL blood flow and diameter confirmed the findings from our recent study (de Tarso et al., 2015). In our recent study we reported that the dimensions of the POF were highly correlated with the amount of follicular wall blood flow, and that selection of POF with greater blood flow could lead to improved plasma P4 production by the $\mathrm{CL}$ in beef cattle. Extensive research data has been produced recently outlining how the distinct intraovarian patterns (i.e., presence and location of the CL during the preovulatory period) can interact to produce different vascular profiles on the POF (Ginther et al., 2014a, b, c, 2015) and thus have a potential impact on fertility. However, follicle and CL blood flow profiles have not been compared between distinct animal categories.

Our results demonstrated that greater blood flow was associated with the size of the follicles for both cows and heifers, where cows had larger follicle diameters when compared with heifers. Studies in dairy cattle reported that cows under distinct physiological conditions had larger POF size than heifers (Sartori et al., 2002, 2004; Wolfensona et al., 2004; Wiltbank et al., 2006). Additionally, it has been reported that the maximum diameter of the POF is larger in Bos taurus breeds when compared to Bos indicus (Bó et al., 2003; Sartori and Barros, 2011). However, studying different synchronization protocols in Bos indicus cattle in Brazil, Sá Filho et al. (2009) and Meneghetti et al. (2009) did not find differences in follicle diameter between Nelore cows and heifers, but did find that follicle diameter positively improved pregnancy rates. Likewise, in Bos taurus beef cows, a decrease in pregnancy rates was reported when using GnRH-induced ovulation of small ovulatory-sized follicles (Perry et al., 2005, 2007); however, there was no effect on pregnancy rate when 
follicles within the same size range ovulated spontaneously (Perry et al., 2005). Optimal sizing of ovulating follicles is still a major concern in both the beef (Perry et al., 2005, 2007; Busch et al., 2008) and dairy industry (Wiltbank et al., 2011; Vasconcelos et al., 2013; Bisinotto et al., 2014), especially when modern production systems are dependent on estrous synchronization strategies (Baruselli et al., 2004; Lauderdale, 2008; Pohler et al., 2012) and because less than $50 \%$ of the cycling cows ovulate a follicle with an optimal size (Wiltbank and Pursley, 2014).

Another singular finding in our study was that pregnant beef cows tended to have a greater follicle wall blood flow than non-pregnant cows in data normalized to maximum values. Siddiqui et al. (2009a) observed a greater follicle diameter at the time of the $\mathrm{GnRH}$ treatment and at the time of $\mathrm{AI}$, and a greater follicle blood flow at the time of $\mathrm{AI}$ in dairy heifers that became pregnant compared with non-pregnant heifers. Similar results have also been described in mares evaluated at the comparable time points, showing that follicle diameter and follicle wall blood flow were greater in mares that became pregnant when compared with nonpregnant animals (Silva et al., 2006). Furthermore, studying endocrine profiles in synchronized lactating Holstein (Lopes et al., 2007), cross-bred Angus cows (Perry et al., 2014), and Murrah buffaloes (Pandey et al., 2011), larger follicle diameters were related to greater plasma estradiol concentrations on the day of AI in cows and buffaloes that were diagnosed pregnant. Although in the present study follicle blood flow was not different between pregnant and non-pregnant cows when data were normalized to ovulation, previous studies supported our findings, since there is a considerable decrease in size and shape of the POF immediately before ovulation in some species (Ginther et al., 1989; Gastal and Gastal, 2011), and it may have interfered with the estimates of blood flow. Therefore, the close association between follicle size and blood flow suggests that greater vascular support to follicles is associated with higher chances of pregnancy, as previously observed for different parameters (i.e., IVF treatments, embryo transfer, and oocyte competence) in women (Bhal et al., 1999, 2001; Coulam et al., 1999; Huey et al., 1999). Nonetheless, a wide range of factors such as the ovulatory capacity of the follicle (Sartori et al., 2001), correlations between hormonal concentrations (Vasconcelos et al., 2013; Martins et al., 2014) and exhibition of estrus during a fixed-time AI protocol (Perry et al., 2014), the length of proestrus (Pohler et al., 2012; Dadarwal et al., 2013), and the maturation of the oocyte (Revah and Butler, 1994; Geary et al., 2013) may interact and affect the fertility outcome in synchronized beef or dairy cattle.

When follicles of cows were divided into follicle size categories (small, medium, and large), larger follicles at the maximum diameter had greater wall blood flow than small follicles, and tended to be more vascularized than medium-size follicles. The positive aspects of a greater blood flow supply and the importance of the maintenance of an appropriate vasculature around the follicle have been studied during the periods of follicle selection and dominance (Acosta et al., 2005; Miura et al., 2014), and also during the preovulatory phase in different species (Brannstorm et al., 1998; Acosta et al., 2003; Gastal et al., 2006; Elsherry et al., 2010; Varughese et al., 2014). Considering that a larger follicle size is associated with a greater follicle blood flow, it is reasonable to assume that a greater blood flow around the follicle might be essential and significant in predicting follicle and oocyte fertility (Huey et al., 1999). Although the methodology of evaluating pixel area in follicles has been broadly used as a standard method to objectively investigate the influence of follicle wall blood flow in different parameters, the different geometries between follicle and CL and area of visual blood flow evaluation at the apparent maximum vascularity suggests that this technique is more reliable and applicable to CLs.

Pearson correlations of follicle diameter and follicle blood flow from each follicle category showed a positive pattern of increase according to the increase in follicle size. Recently, we did report moderate $(r=0.46$ - 0.58) correlations between POF diameter and blood flow, albeit without follicle categorization (de Tarso et al., 2015). Contradicting results were found in dairy buffalos (Varughese et al., 2014), where larger follicles $(>16 \mathrm{~mm})$ had lower follicle wall blood flow when compared with smaller follicles. The former study also obtained a weak Pearson correlation coefficient $(\mathrm{r}=0.21)$ between POF diameter and blood flow using the pixel counting technique, which supports the current pixel data findings. In this study, the linear increase between blood flow and diameter seemed to be even stronger when the follicles were divided into categories, demonstrating how follicle size development is followed with vascularity in a continuous manner.

Potentially due to the small sample size in our study, pregnancy rates were similar when comparing the follicle categories. Perry et al. (2005) showed in beef cattle that GnRH-induced ovulation of follicles $\leq 11.3 \mathrm{~mm}$ was associated with an increase in late embryonic/early fetal mortality; again, however, these effects were not seen in spontaneously ovulated follicles of the same size. In dairy cows, when ovulation occurred in very large follicles $(>17 \mathrm{~mm})$, the fertility was reduced when compared to cows that ovulated follicles between 11 to $17 \mathrm{~mm}$ (Vasconcelos et al., 2013). Siddiqui et al. (2009b) reported that greater vascular perfusion of the follicular wall was associated with higher rates of oocyte recovery, oocyte cleavage, and embryo development in Holstein heifers. Moreover, in a study in humans, Bhal et al. (2001) described follicle blood flow as an important factor in predicting the success of pregnancy establishment after intrauterine insemination. Also in humans, studies have shown the association of a greater blood flow in the wall of the POF and an increase in rates of in vitro fertilization (IVF; Bhal et al., 1999; Coulam et al., 1999; Huey et al., 1999).

No differences regarding CL diameter, or CL blood flow, and the P4 plasma concentrations between cows and heifers and pregnant and non-pregnant cows were seen. Vasconcelos et al. (2001) showed that reducing the size of the ovulatory follicle by follicular 
aspiration caused a reduction in size of the resultant CL and circulating progesterone concentration in lactating dairy cows. Herzog et al. (2011) investigated changes in the luteal blood flow during the first three weeks of pregnancy in dairy cows and observed that pregnant and non-pregnant cows had similar CL blood flow until day 15. Therefore, considering that the $\mathrm{CL}$ receives the greatest rate of blood flow per unit of tissue and that it is the most highly vascularized organ in the body (Wiltbank et al., 1988), no apparent differences in luteal blood flow would be expected during the early angiogenesis in CL development between pregnant and non-pregnant cows.

In conclusion, synchronized beef cows had larger follicle diameter and greater follicle blood flow than heifers. Furthermore, follicle wall blood flow was closely associated with an increase in follicle diameter, whereas smaller follicles had lower follicle wall blood flow when compared with larger follicles. Pregnant cows tended to have a larger follicle diameter and greater follicle blood flow than non-pregnant cows. Furthermore, although it is reasonable to assume, based on the reported literature, that there is a positive influence of follicle blood flow on pregnancy rates, in this study this was not seen, potentially because of the low number of animals in each follicle size category group and the reduced power of the statistical test. Therefore, hormonal regulation in stimulating follicle growth during synchronization protocols needs to be seen as an important and complex interaction among endocrine profile, follicle health (blood flow/size), and oocyte viability to improve fertility in cattle.

\section{Acknowledgments}

The authors gratefully acknowledge Dr. Rebecca Atkinson, Mr. George Wiedlocher, and Mr. William Ortiz for technical assistance with logistics for the study. Special thanks to Mr. Peter Brunelli, Managing Director, Universal Imaging, for providing technical assistance and training with the ultrasound equipment. This work was supported by Southern Illinois University, Carbondale, IL. S.G.S de Tarso was the recipient of a $\mathrm{PhD}$ scholarship from the National Council for Scientific and Technological Development (CNPq), Brazil.

\section{References}

Acosta TJ, Yoshizawa N, Ohtani M, Miyamoto A 2002. Local changes in blood flow within the early and midcycle corpus luteum after prostaglandin $\mathrm{F}(2$ alpha) injection in the cow. Biol Reprod, 66:651-658.

Acosta TJ, Hayashi KG, Ohtani M, Miyamoto A 2003. Local changes in blood flow within the preovulatory follicle wall and early corpus luteum in cows. Reproduction, 125:759-767.

Acosta TJ, Miyamoto A. 2004. Vascular control of ovarian function: ovulation, corpus luteum formation and regression. Anim Reprod Sci, 82/83:127-140.

Acosta TJ, Hayashi KG, Matsui M, Miyamoto A. 2005. Changes in follicular vascularity during the first follicular wave in lactating cows. $J$ Reprod Dev, 51:273280 .

Adams GP, Jaiswal R, Singh J, Malhi P. 2008. Progress in understanding ovarian follicular dynamics in cattle. Theriogenology, 69:72-80.

Atkins JA, Smith MF, Wells KJ, Geary TW. 2010a. Factors affecting preovulatory follicle diameter and ovulation rate after gonadotropin-releasing hormone in postpartum beef cows. Part I: Cycling cows. J Anim Sci, 88:2300-2310

Atkins JA, Smith MF, Wells KJ, Geary TW. 2010 b. Factors affecting preovulatory follicle diameter and ovulation rate after gonadotropin-releasing hormone in postpartum beef cows. Part II: Anestrous cows. J Anim Sci, 88:2311-2320.

Baruselli PS, Reis EL, Marques MO, Nasser LF, Bó GA. 2004. The use of hormonal treatments to improve reproductive performance of anestrous beef cattle in tropical climates. Anim Reprod Sci, 82/83:479-486.

Bhal PS, Pugh ND, Chui DK, Gregory L, Walker SM, Shaw RW. 1999. The use of transvaginal power Doppler ultrasonography to evaluate the relationship between perifollicular vascularity and outcome in invitro fertilization treatment cycles. Hum Reprod, 14:939-945.

Bhal PS, Pugh ND, Gregory L, O'Brien S, Shaw RW. 2001. Perifollicular vascularity as a potential variable affecting outcome in stimulated intrauterine insemination treatment cycles: a study using transvaginal power Doppler. Hum Reprod, 16:16821689.

Bisinotto RS, Ribeiro ES, Santos JEP. 2014. Synchronisation of ovulation for management of reproduction in dairy cows. Animal, 8(Suppl 1):151159.

Bó GA, Baruselli PS, Martínez MF. 2003. Pattern and manipulation of follicular development in Bos indicus cattle. Anim Reprod Sci, 78:307-326.

Bó GA, Baruselli PS, Mapletoft RJ. 2012. Increasing pregnancies following synchronization of bovine recipients. Anim Reprod, 9:312-317.

Bourne TH, Jurkovic D, Waterstone J, Campbell S, Collins P. 1991. Intrafollicular blood flow during human ovulation. Ultrasound Obstet Gynecol, 1:53-59.

Brannstorm M, Zackrisson $\mathbf{U}$, Josefsson B, Granberg S, Collins WP, Bourne T. 1998. Preovulatory changes of blood flow in different regions of the human follicle. Fertil Steril, 69:435-442.

Busch DC, Atkins JA, Bader JF, Schafer DJ, Patterson DJ, Geary TW, Smith MF. 2008. Effect of ovulatory follicle size and expression of estrus on progesterone secretion in beef cows. $J$ Anim Sci, 86:553-563.

Colazo MG, Kastelic JP, Davis H, Rutledge MD, Martinez MF, Small JA, Mapletoft RJ. 2008. Effects of plasma progesterone concentrations on LH release and ovulation in beef cattle given GnRH. Domest Anim Endocrinol, 34:109-117.

Coulam CB, Goodman C, Rinehart JS. 1999. Colour Doppler indices of follicular blood flow as predictors of pregnancy after in-vitro fertilization and embryo transfer. Hum Reprod, 14:1979-1982. 
Dadarwal D, Mapletoft RJ, Adams GP, Pfeifer LFM, Creelman C, Singh J. 2013. Effect of progesterone concentration and duration of proestrus on fertility in beef cattle after fixed-time artificial insemination. Theriogenology, 79:859-866.

de Tarso SGS, Gastal GDA, Bashir ST, Gastal MO, Apgar GA, Gastal EL. 2015. Follicle vascularity coordinates corpus luteum blood flow and progesterone production. Reprod Fertil Dev. doi:http://dx.doi.org/ 10.1071/RD15223

Dias CC, Wechsler FS, Day ML, Vasconcelos JLM. 2009. Progesterone concentrations, exogenous equine chorionic gonadotropin, and timing of prostaglandin F2 $\alpha$ treatment affect fertility in postpuberal Nelore heifers. Theriogenology, 72:378-385.

El-sherry TM, Matsui M, Miyake Y. 2010. Haemodynamic changes of the superovulated follicle as a cause of superovulation variability in cattle. $J \mathrm{Am} \mathrm{Sci}$, 6:744-751

Eversole DE, Browne MF, Hall JB, Dietz RE. 2009. Body condition scoring beef cows. Blacksburg, VA: Virginia Tech. Publications and Educcational Resources. Available on: https//pubs. ext.vt.edu/400/ 400-795/400-795.html.

Gastal EL, Gastal MO, Ginther OJ. 2006 Relationships of changes in B-mode echotexture and colour-Doppler signals in the wall of the preovulatory follicle to changes in systemic oestradiol concentrations and the effects of human chorionic gonadotrophin in mares. Reproduction, 131:699-709.

Gastal EL, Gastal MO. 2011. Equine preovulatory follicle: blood flow changes, prediction of ovulation and fertility. Rev Bras Reprod Anim, 35:239-252.

Geary TW, Smith MF, Macneil MD, Day ML, Bridges GA, Perry GA, Abreu FM, Atkins JA, Pohler KG, Jinks EM, Madsen CA. 2013. Influence of follicular characteristics at ovulation on early embryonic survival. J Anim Sci, 91:3014-3021.

Gimenes LU, Sá Filho MF, Carvalho NAT, TorresJúnior JRS, Souza AH, Madureira EH, Trinca LA, Sartorelli ES, Barros CM, Carvalho JBP, Mapletoft RJ, Baruselli PS. 2008. Follicle deviation and ovulatory capacity in Bos indicus heifers. Theriogenology, 69:852-858.

Ginther OJ, Knopf L, Kastelic JP. 1989. Temporal associations among ovarian events in cattle during oestrous cycles with two and three follicular waves. $J$ Reprod Fertil, 87:223-230.

Ginther OJ. 1995. Ultrasonic Imaging and Animal Reproduction: Book 2, Horses. Cross Plains, WI: Equiservices Publishing.

Ginther OJ, Utt MD. 2004. Doppler ultrasound in equine reproduction: principles, techniques, and potential. J Equine Vet Sci, 24:516-526.

Ginther OJ. 2007. Ultrasonic Imaging and Animal Reproduction: Book 4, Color-Doppler ultrasonography. Cross Plains, WI: Equiservices Publishing.

Ginther OJ, Gastal EL, Gastal MO, Utt MD, Beg MA. 2007. Luteal blood flow and progesterone production in mares. Anim Reprod Sci, 99:213-220.

Ginther OJ, Rakesh HB, Hoffman MM. 2014a. Blood flow to follicles and CL during development of the periovulatory follicular wave in heifers. Theriogenology, 82:304-311.

Ginther OJ, Rakesh HB, Hoffman MM. 2014b. Complex interrelationships among CL, preovulatory follicle, number of follicular waves, and right or left ovaries in heifers. Theriogenology, 81:481-489.

Ginther OJ, Siddiqui MAR, Baldrighi JM, Hoffman MM. 2014c. Effect of intraovarian proximity between dominant follicle and corpus luteum on dimensions and blood flow of each structure in heifers. Theriogenology, 82:875-883.

Ginther OJ, Siddiqui MAR, Baldrighi JM, Hoffman MM. 2015. Conversion of intraovarian patterns from preovulation to postovulation based on location of dominant follicle and corpus luteum in heifers. Theriogenology, 83:153-161.

Herzog K, Bollwein H. 2007. Application of Doppler ultrasonography in cattle reproduction. Reprod Domest Anim, 42:51-58.

Herzog K, Voss C, Kastelic JP, Beindorff N, Paul V, Niemann H, Bollwein H. 2011. Luteal blood flow increases during the first three weeks of pregnancy in lactating dairy cows. Theriogenology, 75:549-554.

Huey S, Abuhamad A, Barroso G, Hsu MI, Kolm P, Mayer J, Oehninger S. 1999. Perifollicular blood flow Doppler indices, but not follicular $\mathrm{pO} 2, \mathrm{pCO} 2$, or $\mathrm{pH}$, predict oocyte developmental competence in in vitro fertilization. Fertil Steril, 72:707-712.

Janson PO, Damber JE, Axén C. 1981. Luteal blood flow and progesterone secretion in pseudopregnant rabbits. J Reprod Fertil, 63:491-497.

Lamb GC, Stevenson JS, Kesler DJ, Garverick HA, Brown DR, Salfen BE. 2001. Inclusion of an intravaginal progesterone insert plus GnRH and prostaglandin F2alpha for ovulation control in postpartum suckled beef cows. J Anim Sci, 79:22532259.

Lauderdale JW. 2008. ASAS Centennial Paper: contributions in the Journal of Animal Science to the development of protocols for breeding management of cattle through synchronization of estrus and ovulation. $J$ Anim Sci, 87:801-812.

Lopes AS, Butler ST, Gilbert RO, Butler WR. 2007. Relationship of pre-ovulatory follicle size, estradiol concentrations and season to pregnancy outcome in dairy cows. Anim Reprod Sci, 99:34-43.

Lopez H, Satter LD, Wiltbank MC. 2004. Relationship between level of milk production and estrous behavior of lactating dairy cows. Appl Anim Behav Sci, 81:209-223.

Lopez H, Caraviello DZ, Satter LD, Fricke PM, Wiltbank MC. 2005. Relationship between level of milk production and multiple ovulations in lactating dairy cows. J Dairy Sci, 88:2783-2793.

Macmillan KL, Segwagwe BVE, Pino CS. 2003. Associations between the manipulation of patterns of follicular development and fertility in cattle. Anim Reprod Sci, 78:327-344.

Martins T, Peres RFG, Rodrigues ADP, Pohler KG, Pereira MHC, Day ML, Vasconcelos JLM. 2014. Effect of progesterone concentrations, follicle diameter, timing of artificial insemination, and ovulatory stimulus 
on pregnancy rate to synchronized artificial insemination in postpubertal Nellore heifers. Theriogenology, 81:446-453.

Meneghetti M, Filho OGS, Peres RFG, Lamb GC, Vasconcelos JLM. 2009. Fixed-time artificial insemination with estradiol and progesterone for Bos indicus cows I: basis for development of protocols. Theriogenology, 72:179-189.

Miró J, Vilés K, Anglada O, Marín H, Jordana J, Crisci A. 2015. Color Doppler provides a reliable and rapid means of monitoring luteolysis in female donkeys. Theriogenology, 83:485-490.

Miura R, Haneda S, Lee H-H, Miyamoto A, Shimizu T, Miyahara K, Miyake Y-I, Matsui M. 2014. Evidence that the dominant follicle of the first wave is more active than that of the second wave in terms of its growth rate, blood flow supply and steroidogenic capacity in cows. Anim Reprod Sci, 145:114-122.

Oliveira MEF, Feliciano MAR, D'Amato CC, Oliveira LG, Bicudo SD, Fonseca JF, Vicente WRR, Visco E, Bartlewski PM. 2014. Correlations between ovarian follicular blood flow and superovulatory responses in ewes. Anim Reprod Sci, 144:30-37.

Pandey AK, Dhaliwal GS, Ghuman SPS, Agarwal SK. 2011. Impact of pre-ovulatory follicle diameter on plasma estradiol, subsequent luteal profiles and conception rate in buffalo (Bubalus bubalis). Anim Reprod Sci, 123:169-174.

Perry GA, Smith MF, Lucy MC, Green JA, Parks TE, MacNeil MD, Roberts AJ, Geary, TW. 2005. Relationship between follicle size at insemination and pregnancy success. Proc Natl Acad Sci USA, 102:52685273.

Perry GA, Smith MF, Roberts AJ, MacNeil MD, Geary TW. 2007. Relationship between size of the ovulatory follicle and pregnancy success in beef heifers. J Anim Sci, 85:684-689.

Perry GA, Swanson OL, Larimore EL, Perry BL, Djira GD, Cushman RA. 2014. Relationship of follicle size and concentrations of estradiol among cows exhibiting or not exhibiting estrus during a fixed-time AI protocol. Domest Anim Endocrinol, 48:15-20.

Pfeifer LFM, Mapletoft RJ, Kastelic JP, Small JA, Adams GP, Dionello NJ, Singh J. 2009. Effects of low versus physiologic plasma progesterone concentrations on ovarian follicular development and fertility in beef cattle. Theriogenology, 72:1237-1250.

Pohler KG, Geary TW, Atkins JA, Perry GA, Jinks EM, Smith MF. 2012. Follicular determinants of pregnancy establishment and maintenance. Cell Tissue Res, 349:649-664.

Revah I, Butler WR. 1994. Prolonged dominance of follicles and reduced viability of bovine oocytes. $J$ Reprod Fertil, 106:39-47.

Sá Filho MF, Crespilho AM, Santos JEP, Perry GA, Baruselli PS. 2010. Ovarian follicle diameter at timed insemination and estrous response influence likelihood of ovulation and pregnancy after estrous synchronization with progesterone or progestin-based protocols in suckled Bos indicus cows. Anim Reprod Sci, 120:23-30.

Sá Filho OG, Meneghetti M, Peres RFG, Lamb GC,
Vasconcelos JLM. 2009. Fixed-time artificial insemination with estradiol and progesterone for Bos indicus cows. II: strategies and factors affecting fertility. Theriogenology, 72:210-218.

Sartori R, Fricke PM, Ferreira JC, Ginther OJ, Wiltbank MC. 2001. Follicular deviation and acquisition of ovulatory capacity in bovine follicles. Biol Reprod, 65:1403-1409.

Sartori R, Rosa GJM, Wiltbank MC. 2002. Ovarian structures and circulating steroids in heifers and lactating cows in summer and lactating and dry cows in winter. J Dairy Sci, 85:2813-2822.

Sartori R, Haughian JM, Shaver RD, Rosa GJM, Wiltbank MC. 2004. Comparison of ovarian function and circulating steroids in estrous cycles of Holstein heifers and lactating cows. J Dairy Sci, 87:905-920.

Sartori R, Barros CM. 2011. Reproductive cycles in Bos indicus cattle. Anim Reprod Sci, 124:244-250.

Siddiqui MAR, Almamun M, Ginther OJ. 2009a. Blood flow in the wall of the preovulatory follicle and its relationship to pregnancy establishment in heifers. Anim Reprod Sci, 113:287-292.

Siddiqui MAR, Gastal EL, Gastal MO, Almamun M, Beg MA, Ginther OJ. 2009b. Relationship of vascular perfusion of the wall of the preovulatory follicle to in vitro fertilisation and embryo development in heifers. Reproduction, 137:689-697.

Silva LA, Gastal EL, Gastal MO, Beg MA, Ginther OJ. 2006. Relationship between vascularity of the preovulatory follicle and establishment of pregnancy in mares. Anim Reprod, 3:339-346.

Taylor R. 1990. Interpretation of the correlation coefficient: a basic review. J Diagnostic Med Sonogr, 6:35-39.

Varughese EE, Brar PS, Honparkhe M, Ghuman SPS. 2014. Correlation of blood flow of the preovulatory follicle to its diameter and endocrine profile in dairy buffalo. Reprod Domest Anim, 49:140144.

Vasconcelos JLM, Sartori R, Oliveira HN, Guenther JG, Wiltbank MC. 2001. Reduction in size of the ovulatory follicle reduces subsequent luteal size and pregnancy rate. Theriogenology, 56:307-314.

Vasconcelos JLM, Pereira MHC, Meneghetti M, Dias CC, Sá Filho OG, Peres RFG. 2013. Relationships between growth of the preovulatory follicle and gestation success in lactating dairy cows. Anim Reprod, 10:206-214.

Viana JHM, Arashiro EKN, Siqueira LGB, Ghetti AM, Areas VS, Guimarães CRB. 2013. Doppler ultrasonography as a tool for ovarian management. Anim Reprod, 10:215-222.

Wiltbank MC, Dysko RC, Gallagher KP, Keyes PL. 1988. Relationship between blood flow and steroidogenesis in the rabbit corpus luteum. $J$ Reprod Fertil, 84:513-520.

Wiltbank MC, Lopez H, Sartori R, Sangsritavong S, Gümen A. 2006. Changes in reproductive physiology of lactating dairy cows due to elevated steroid metabolism. Theriogenology, 65:17-29.

Wiltbank MC, Sartori R, Herlihy MM, Vasconcelos J, Nascimento A, Souza A, Ayres H, Cunha A, 
Keskin A, Guenther JN, Gumen A. 2011. Managing the dominant follicle in lactating dairy cows. Theriogenology, 76:1568-1582.

Wiltbank MC, Pursley JR. 2014. The cow as an induced ovulator: timed AI after synchronization of ovulation. Theriogenology, 81:170-185.

Wiltbank MC, Souza AH, Carvalho PD, Cunha AP, Giordano JO, Fricke PM, Baez GM, Diskin MG.
2014. Physiological and practical effects of progesterone on reproduction in dairy cattle. Animal, 8(Suppl 1):70-81.

Wolfensona D, Inbara G, Rotha Z, Kaimb M, Blocha A, Braw-Talb R. 2004. Follicular dynamics and concentrations of steroids and gonadotropins in lactating cows and nulliparous heifers. Theriogenology, 62, 10421055 . 